\title{
Role of Inorganic and Organic Fractions in Animal Manure Compost in Lead Immobilization and Microbial Activity in Soil
}

\author{
Masahiko Katoh, ${ }^{1,2}$ Wataru Kitahara, ${ }^{3,4}$ and Takeshi Sato ${ }^{2}$ \\ ${ }^{1}$ Department of Agricultural Chemistry, School of Agriculture, Meiji University, 1-1-1 Higashi-Mita, Tama-ku, \\ Kanagawa 214-8571, Japan \\ ${ }^{2}$ Department of Civil Engineering, Faculty of Engineering, Gifu University, 1-1 Yanagido, Gifu 501-1193, Japan \\ ${ }^{3}$ Department of Civil Engineering, Graduate School of Engineering, Gifu University, 1-1 Yanagido, Gifu 501-1193, Japan \\ ${ }^{4}$ In Situ Solutions Co., Ltd., 2-5-2 Kandasudamachi, Chiyoda-ku, Tokyo 101-0041, Japan \\ Correspondence should be addressed to Masahiko Katoh; mkatoh@meiji.ac.jp
}

Received 20 November 2015; Accepted 15 December 2015

Academic Editor: Ezio Ranieri

Copyright (C) 2016 Masahiko Katoh et al. This is an open access article distributed under the Creative Commons Attribution License, which permits unrestricted use, distribution, and reproduction in any medium, provided the original work is properly cited.

This study aimed to identify how the ratio of inorganic-to-organic components in animal manure compost (AMC) affected both lead immobilization and microbial activity in lead-contaminated soil. When AMC containing $50 \%$ or more inorganic fraction with high phosphorous content was applied to contaminated soil, the amounts of water-soluble lead in it were suppressed by over $88 \%$ from the values in the soil without compost. The residual fraction under sequential extraction increased with the inorganic fraction in the AMC; however, in those AMCs, the levels of microbial enzyme activity were the same or less than those in the control soil. The application of AMC containing $25 \%$ inorganic fraction could alter the lead phases to be more insoluble while improving microbial enzyme activities; however, no suppression of the level of water-soluble lead existed during the first 30 days. These results indicate that compost containing an inorganic component of $50 \%$ or more with high phosphorus content is suitable for immobilizing lead; however, in the case where low precipitation is expected for a month, AMC containing $25 \%$ inorganic component could be used to both immobilize lead and restore microbial activity.

\section{Introduction}

Lead is one of the most common and harmful heavy-metal soil contaminants worldwide, particularly near mines and shooting ranges. Lead contamination in the soil of such sites poses a risk to human and animal health as well as plant growth. Thus, its mobility and bioavailability should be reduced by appropriate treatments. In addition, the rehabilitation of soil ecosystems that have undergone destruction by lead contamination should be accomplished through the remediation of such soil. Since contamination in these sites is extensive and asset values are extremely low, chemical immobilization capable of transforming lead into less soluble phases is a cost-effective remediational approach. Thus, various immobilization materials have been studied and developed [1-7].
Animal manure compost (AMC), which is the most abundantly found organic waste material in Japan, can immobilize heavy metals and improve plant growth and microbial activity [8-16] by supplying nutrients to plant and soil biota. Therefore, in addition to lead immobilization, the application of AMC to lead-contaminated soil can help rehabilitate soil ecosystems, which inorganic immobilization materials cannot [17]. Numerous studies have investigated the effectiveness of AMC for lead immobilization [18, 19]; however, consistent conclusions on the mechanisms behind this process have not been obtained as such immobilization that greatly depends upon the AMC type, that is, AMC's physicochemical properties. In particular, the presence of both inorganic and organic components in AMC makes it complicated to understand lead immobilization. 
TABLE 1: Physicochemical properties of contaminated soil used in this study (on the basis of air-dried weight).

\begin{tabular}{|c|c|c|c|c|c|c|c|c|c|c|c|c|}
\hline Sand & Silt & Clay & $\mathrm{pH}$ & TC & $\mathrm{TN}$ & $\mathrm{WSOC}^{\mathrm{a}}$ & WS-Pb & & & & & Amorphous Fe \\
\hline$(\%)$ & $(\%)$ & $(\%)$ & & $\left(\mathrm{g} \mathrm{kg}^{-1}\right)$ & $\left(\mathrm{g} \mathrm{kg}^{-1}\right)$ & $\left(\mathrm{mg} \mathrm{kg}^{-1}\right)$ & $\left(\mathrm{mg} \mathrm{kg}^{-1}\right)$ & $\mathrm{Pb}\left(\mathrm{g} \mathrm{kg}^{-1}\right)$ & $\mathrm{P}\left(\mathrm{g} \mathrm{kg}^{-1}\right)$ & $\mathrm{Al}\left(\mathrm{g} \mathrm{kg}^{-1}\right)$ & $\mathrm{Fe}\left(\mathrm{g} \mathrm{kg}^{-1}\right)$ & $\left(\mathrm{g} \mathrm{kg}^{-1}\right)$ \\
\hline 81.5 & 9.5 & 9.0 & 7.3 & 6.0 & 0.0 & 139 & 35 & 4.40 & 0.40 & 13.1 & 33.8 & 1.3 \\
\hline
\end{tabular}

${ }^{\mathrm{a}}$ Water-soluble organic carbon.

${ }^{\mathrm{b}}$ Water-soluble lead.

Lead immobilization by AMC can be separated into indirect and direct mechanisms. The typical indirect mechanisms of lead immobilization are explained by the $\mathrm{pH}$ increase owing to the alkalinity of the inorganic component in AMC; this $\mathrm{pH}$ increase can promote the precipitation of lead carbonate and hydroxide minerals, resulting in a reduction of lead mobility and bioavailability $[1,20]$. The direct mechanisms of lead immobilization by AMC have been considered to be the reaction of the lead with the inorganic and organic components in AMC. Phosphorus, sulfate, and iron in the inorganic component and humic substances in the organic component in AMC seem to be the sources responsible for the reaction with lead [10, 18, 21-23]. Katoh et al. [24] applied a specific method for the fractionation of the inorganic and acid-insoluble organic components from AMC to elucidate their separate contributions to lead immobilization. They indicated that the inorganic component in AMC could immobilize lead more effectively than its organic components [24]. These results imply that the inorganic component in AMC has a crucial role in lead immobilization, and AMC with a higher inorganic content is more suitable. However, to rehabilitate microbial activity, the organic component in $\mathrm{AMC}$ is also required since it supplies sufficient nutrients to soil microorganisms [17]. This component, however, may negatively affect lead mobility; water-soluble organic matter in AMC reacts and forms complexes with lead ions, resulting in enhancements in lead mobility. Therefore, a suitable ratio of inorganic and organic components in AMC should be clarified to reduce the mobility and bioavailability of lead and enhance the microbial activities in the soil. AMC has a wide range of the inorganic-to-organic component ratios [25]; however, to our knowledge, the optimal ratio of inorganicto-organic components in AMC for lead immobilization and the rehabilitation of microbial activity have not been studied.

We investigated the mobility and bioavailability of the lead, lead phases, and microbial activities in soil amended with the AMCs of various inorganic-to-organic component ratios. The inorganic fraction was derived from swine manure compost and the acid-insoluble organic fraction was derived from cattle manure compost. These fractions can immobilize lead more effectively than other AMCs owing to the high content of phosphorus and mature organic matter in the inorganic and acid-insoluble organic fractions, respectively [24]. We aimed to identify how the ratio of inorganicto-organic components in AMC affected the mobility and bioavailability of lead, lead phase, and microbial activity. On the basis of the obtained results, we discuss the optimal ratio of the inorganic and organic components in AMC to immobilize lead and rehabilitate microbial activity in soil.
TABle 2: Chemical properties of inorganic and acid-insoluble organic fractions used in this study (on the basis of air-dried weight, $\left.\mathrm{mg} \mathrm{g}^{-1}\right)[24]$.

\begin{tabular}{|c|c|c|}
\hline Characteristic & Inorganic fraction & $\begin{array}{c}\text { Acid-insoluble } \\
\text { organic fraction }\end{array}$ \\
\hline Total calcium & 152 & $\mathrm{ND}^{* 1}$ \\
\hline Total magnesium & 44 & ND \\
\hline Total potassium & 53 & ND \\
\hline Total iron & 7 & ND \\
\hline Total phosphorus & 131 & ND \\
\hline Total carbon & ND & 452 \\
\hline $\mathrm{ADF}-\mathrm{C}^{* 2}$ & ND & 344 \\
\hline Humic acid carbon & ND & 25 \\
\hline Fulvic acid carbon & ND & 52 \\
\hline
\end{tabular}

${ }^{* 1}$ Not determined.

${ }^{* 2}$ Acid detergent fiber carbon.

\section{Materials and Methods}

2.1. Preparation of Soil. The lead-contaminated soil used herein was collected from depths of $5-15 \mathrm{~cm}$ at a shooting range located at $35^{\circ} 28^{\prime} 6^{\prime \prime} \mathrm{N}$ and $137^{\circ} 29^{\prime} 2^{\prime \prime} \mathrm{E}$ in Gifu, Japan. The soil sample was air-dried, passed through a $2 \mathrm{~mm}$ sieve, and was used for chemical analysis and incubation tests. The selected physicochemical properties of the soil used are shown in Table 1 . The soil had a sandy loam texture. The total lead content of the soil was $4.40 \mathrm{~g} \mathrm{~kg}^{-1}$ and the soil $\mathrm{pH}$ was 7.3 .

2.2. Preparation of Animal Manure Compost. Commercial swine and cattle manure composts were used herein to obtain the inorganic and acid-insoluble organic fractions, respectively. We selected these composts since each fraction of the compost can immobilize lead more effectively than other composts [24]. The fractionation followed the method described by Katoh et al. [24]. In brief, the swine manure compost was combusted at $600^{\circ} \mathrm{C}$ for $2 \mathrm{~h}$; the residue after combustion was used as the inorganic fraction. The cattle manure compost was subjected to extraction with $1 \mathrm{M} \mathrm{HCl}$ for $1 \mathrm{~h}$ to remove almost all inorganic components, and the residue after extraction was used as the acid-insoluble organic fraction. The $\mathrm{pH}$ of each fraction was adjusted to 7 to match that of the soil. Table 2 shows the selected chemical properties of each fraction [24]. The calcium, magnesium, potassium, iron, and phosphorus contents in the inorganic fraction were $152,44,53,7$, and $131 \mathrm{mg} \mathrm{g}^{-1}$, respectively; moreover, the total, acid-detergent fiber, humic acid, and fulvic acid carbon 
contents in the acid-insoluble organic fraction were 452, 344, 25 , and $52 \mathrm{mg} \mathrm{g}^{-1}$, respectively [24]. After $\mathrm{pH}$ adjustment, the fractions were well mixed at the inorganic-to-acid-insoluble organic fraction ratios of 100/0,75/25, 50/50, 25/75, and 0/100; the mixed samples were used as the AMCs herein (hereafter referred to AMC with inorganic-to-organic ratios of 100/0, $75 / 25,50 / 50,25 / 75$, and 0/100).

2.3. Soil-Incubation Experiment. The contaminated soil was mixed with each AMC sample at $10 \mathrm{wt} \%$ and incubated at room temperature $\left(25^{\circ} \mathrm{C}\right)$ for 184 days. Soil without AMC was also prepared as a control. Three replicates were prepared for each treatment. The water content in the soil was maintained at $60 \%$ of its maximum water-holding capacity during the incubation period. Soil samples were collected at $0,7,30,90$, and 184 days; the samples were freeze-dried and analyzed to determine the levels of water-soluble lead and water-soluble organic carbon. The soil sampled on day 184 was analyzed to assess lead phases by sequential extraction and microbial enzyme activities. Herein, the level of water-soluble lead was employed as an indicator of lead mobility and bioavailability in the soil, because its water-soluble form is easily mobile and utilized by plant and soil biota.

Another soil-incubation experiment was conducted to evaluate $\mathrm{CO}_{2}$ emission from the soil with the AMCs with inorganic-to-organic ratios of $100 / 0,50 / 50$, and $0 / 100$. A $100 \mathrm{~mL}$ polypropylene bottle including the soil with and without the AMC, and two glass beakers-one having $0.5 \mathrm{M}$ $\mathrm{NaOH}$ and the other having $0.5 \mathrm{M} \mathrm{H}_{2} \mathrm{SO}_{4}$-were placed into a $5 \mathrm{~L}$ glass bottle and incubated at room temperature $\left(25^{\circ} \mathrm{C}\right)$. A $5 \mathrm{~L}$ bottle without soil was also prepared. Three replicates were prepared for each treatment. At days 7, 14, 30, 60, 120 , and 194, the glass beaker containing $0.5 \mathrm{M} \mathrm{NaOH}$ was replaced with a fresh $0.5 \mathrm{M} \mathrm{NaOH}$-containing beaker. The collected $\mathrm{NaOH}$ was titrated with $0.2 \mathrm{M} \mathrm{HCl}$ and the $\mathrm{CO}_{2}$ emission was calculated from the following equation:

$$
C_{s}=\frac{V \times F-C_{b}}{S},
$$

where $C_{s}$ is the amount of $\mathrm{CO}_{2}$ emission $\left(\mathrm{mol} \mathrm{g}\right.$-soil $\left.^{-1}\right), \mathrm{V}$ is the amount of $0.2 \mathrm{M} \mathrm{HCl}$ titrated $(\mathrm{mL}), F$ is the factor of $0.2 \mathrm{M}$ $\mathrm{HCl}\left(\mathrm{mol}-\mathrm{CO}_{2} \mathrm{~mL}^{-1}\right), C_{b}$ is the amount of $\mathrm{CO}_{2}$ emission in the blank (mol), and $S$ is the amount of soil $(10.0 \mathrm{~g})$. The $\mathrm{CO}_{2}$ emission derived from AMC was calculated by subtracting the emission by the AMC-treated soil samples from that by the control soil sample.

2.4. Analytical Methods. The soil's $\mathrm{pH}$ value was measured in ultra-pure water using a $\mathrm{pH}$ meter (MM-60M, DKK-TOA Co., Japan). Soil texture was determined using the hydrometer method [26]. The total carbon and nitrogen contents in the soil were determined using a carbon, hydrogen, and nitrogen elemental analyzer (MT-6; Yanaco New Science Inc., Japan).

The water-soluble lead and organic carbon in soil were extracted using ultra-pure water (1:10 soil: solution ratio) and analyzed using an inductively coupled plasma-atomic emission spectrometer (ICP-AES; ULTIMA2; HORIBA Ltd., Japan) and a total organic carbon analyzer $\left(\mathrm{TOC}-\mathrm{V}_{\mathrm{WS}}\right.$;
Shimadzu Co., Japan). The amorphous iron was extracted using Shuman's method [27]. The total lead, phosphorus, aluminum, and iron contents in the soil were determined by acid digestion with $\mathrm{HNO}_{3}$ and $\mathrm{HCl}$ using a microwave. A sequential extraction procedure was performed on the soil samples in accordance with the procedure described by Tessier et al. [28]. In brief, each fraction was extracted with a $1 \mathrm{M} \mathrm{MgCl}_{2}$ solution (exchangeable fraction), $1 \mathrm{M}$ sodium acetate solution at $\mathrm{pH} 5$ (carbonate fraction), $0.04 \mathrm{M}$ $\mathrm{NH}_{2} \mathrm{OH}-\mathrm{HCl}$ in $25 \%(\mathrm{v} / \mathrm{v}) \mathrm{HOAc}$ solution in a water bath at $95^{\circ} \mathrm{C}$ with occasional agitation ( $\mathrm{Fe} / \mathrm{Mn}$ oxide fraction), $0.02 \mathrm{M} \mathrm{HNO}_{3}$ solution, $5 \mathrm{~mL} 30 \% \mathrm{H}_{2} \mathrm{O}_{2}$ solution in a water bath at $85^{\circ} \mathrm{C}$ with occasional agitation (organic fraction), and $5 \mathrm{~mL}$ of $\mathrm{HNO}_{3}$ and $2 \mathrm{~mL}$ of $\mathrm{HCl}$ using a microwave oven (residual fraction). All of the extracted or digested solutions were passed through a $0.45 \mu \mathrm{m}$ filter and analyzed to determine the elemental concentration using ICP-AES.

Three different microbial enzyme activities-dehydrogenase, urease, and saccharase-were measured in the soil sample. The dehydrogenase activity was determined in accordance with the method described by Tabatabai [29] using triphenyltetrazolium chloride. The triphenylformazan produced was measured using spectrophotometry at $485 \mathrm{~nm}$. The urease activity was monitored using the method described by Kandeler and Gerber [30] by measuring the $\mathrm{NH}_{4}{ }^{+}$produced after the incubation of soil with urea. The saccharase activity was determined in accordance with the method described by Frankenberger and Johanson [31].

2.5. Statistical Analysis. Statistical analyses were performed using JMP Ver. 8.0.2 (SAS Institute Inc.). An analysis of variance was used to measure microbial enzyme activities. The differences between the mean values were determined using Tukey's honestly significant difference test at a $95 \%$ confidence level.

\section{Results}

3.1. Soil pH, Water-Soluble Lead, and Organic Carbon in Soil with $A M C$. The $\mathrm{pH}$ in the control soil was not significantly changed and ranged from 7.5 to 7.7 throughout the incubation period (Table 3). Moreover, the soil pH levels in all the AMCs were not significantly different from that in the control, indicating that the soil $\mathrm{pH}$ did not affect the enhancement or reduction in the lead mobility and bioavailability in the soil with AMC.

Figure 1(a) shows the amount of water-soluble lead in the soil with AMC. The amount of water-soluble lead in the control soil ranged from 35 to $44 \mathrm{mg} \mathrm{kg}^{-1}$ throughout the incubation period. The amount of water-soluble lead in the soil treated with AMC with an inorganic-to-organic ratio of $0 / 100$ was higher than that in the control soil throughout the incubation period. The amount of water-soluble lead in the soil treated by AMC with an inorganic-to-organic ratio of $25 / 75$ was equal to or at a higher level than that in the control soil before day 30 , but it decreased to $36 \%$ of that in the control soil on day 184 . The amounts of water-soluble lead in the soil samples treated by AMC with inorganic-to-organic 
TABLE 3: $\mathrm{pH}$ in soils amended with simulated compost during incubation period $(n=3)$.

\begin{tabular}{lcccrr}
\hline $\begin{array}{l}\text { Compost } \\
\text { (Inorganic/organic) }\end{array}$ & 0 & 7 & Days of incubation & \multicolumn{3}{c}{90} \\
\hline $100 / 0$ & $7.7 \pm 0.0$ & $7.5 \pm 0.0$ & $7.6 \pm 0.1$ & $7.8 \pm 0.0$ & $7.8 \pm 0.0$ \\
$75 / 25$ & $7.7 \pm 0.0$ & $7.5 \pm 0.0$ & $7.7 \pm 0.0$ & $7.8 \pm 0.0$ & $7.8 \pm 0.1$ \\
$50 / 50$ & $7.6 \pm 0.0$ & $7.6 \pm 0.0$ & $7.7 \pm 0.1$ & $7.8 \pm 0.0$ & $7.6 \pm 0.0$ \\
$25 / 75$ & $7.4 \pm 0.0$ & $7.4 \pm 0.0$ & $7.8 \pm 0.0$ & 7.0 \\
$0 / 100$ & $7.2 \pm 0.0$ & $7.3 \pm 0.0$ & $7.6 \pm 0.1$ & $7.8 \pm 0.0$ & $7.0 \pm 0.2$ \\
Control & $7.5 \pm 0.1$ & $7.6 \pm 0.0$ & $7.7 \pm 0.0$ & $7.5 \pm 0.2$ \\
\hline
\end{tabular}

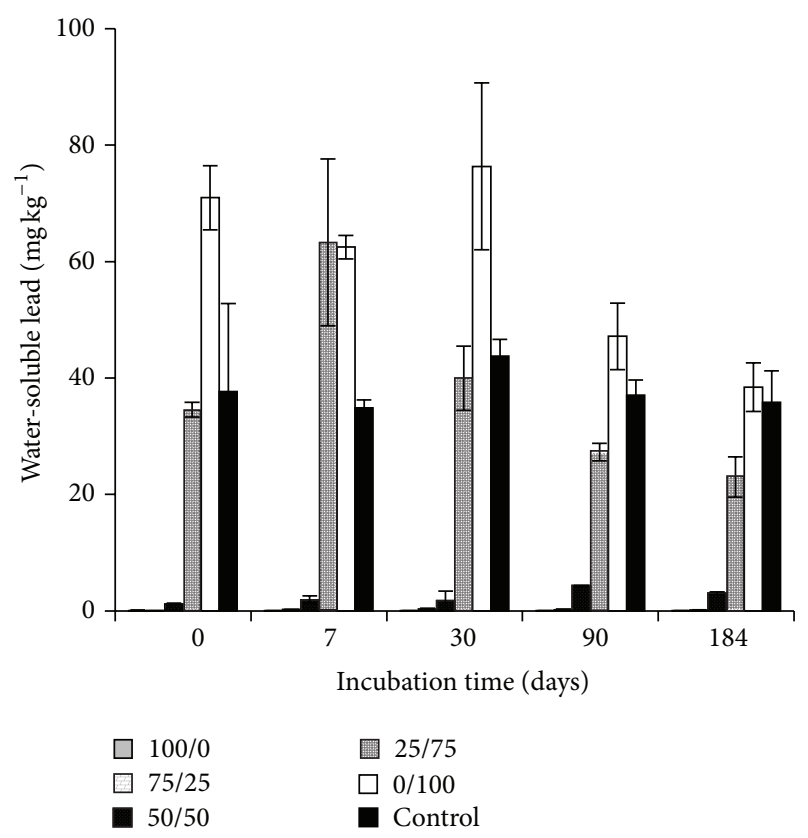

(a)

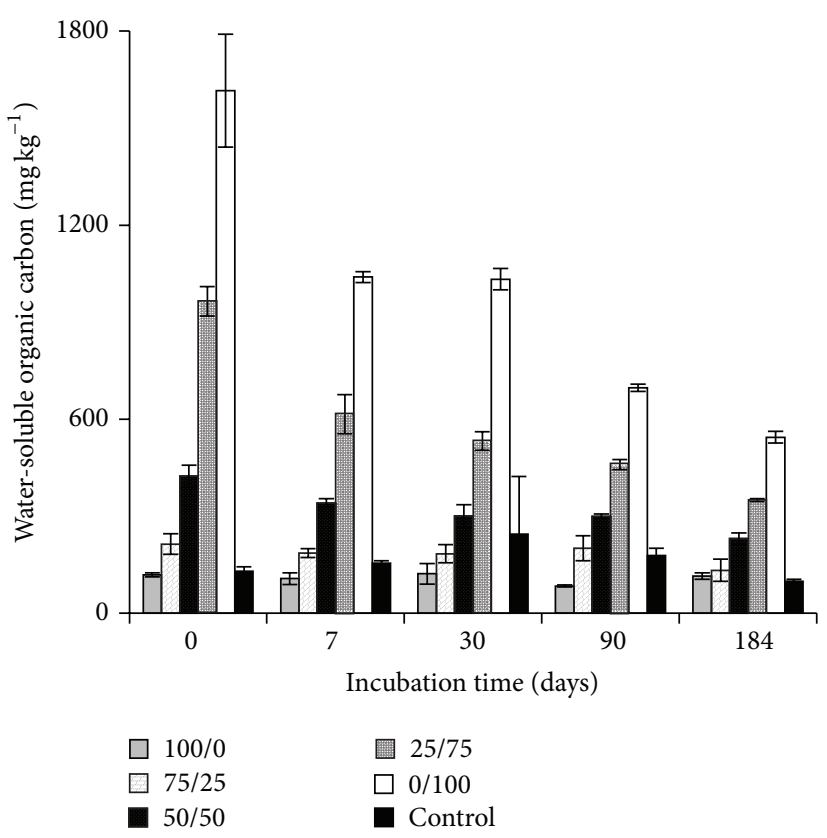

(b)

FIGURE 1: Water-soluble lead (a) and organic carbon (b) in soil amended with AMC of inorganic/organic = 100/0, 75/25, 50/50, 25/75, and $0 / 100$ and without AMC (control). Vertical bars indicate the standard error.

ratios of $50 / 50,75 / 25$, and $100 / 0$ were $3.4 \%-12 \%, 0.1 \%-0.8 \%$, and $0.1 \%-0.2 \%$, respectively, of the value in the control soil. The amount of water-soluble organic carbon in the soil is shown in Figure 1(b). At the beginning of the incubation period, the amounts of water-soluble organic carbon in the soils treated with different AMC compositions were arranged in the following order: inorganic/organic $=0 / 100>$ inorganic/organic $=25 / 75>$ inorganic/organic $=50 / 50>$ inorganic/organic $=75 / 25>$ control $>$ inorganic/organic $=$ $100 / 0$. The amounts of water-soluble organic carbon in the soil treated by AMC with inorganic-to-organic ratios of $50 / 50,75 / 25$, and $100 / 0$ remained at their initial values during the incubation period. The amounts of water-soluble organic carbon in the soil treated by AMC with inorganic-to-organic ratios of $0 / 100$ and 25/75 had rapidly decreased between days 0 and 7 , after which gradual decreases were observed. The decreases in water-soluble organic carbon between days 0 and 184 were 1,071 and $615 \mathrm{mg} \mathrm{kg}^{-1}$ under inorganic-to-organic ratios of $0 / 100$ and $25 / 75$, respectively.
3.2. $\mathrm{CO}_{2}$ Emission from Soil Amended with AMC. The cumulated $\mathrm{CO}_{2}$ emission derived from AMC is shown in Figure 2. The level of $\mathrm{CO}_{2}$ emission from the AMC with an inorganic-to-organic ratio of $0 / 100$ increased during the early stage of incubation and then remained at approximately $500 \mathrm{mg}-\mathrm{C} \mathrm{kg}^{-1}$. The $\mathrm{CO}_{2}$ emission trends from the AMC with inorganic-to-organic ratios of 50/50 and 100/0 were similar; they slightly increased at the beginning of incubation and then remained at approximately $100 \mathrm{mg}-\mathrm{C} \mathrm{kg}^{-1}$.

3.3. Lead Phases by Sequential Extraction in Lead-Contaminated Soil. Figure 3 shows the lead fraction results under sequential extraction. The average recovery, which was defined herein as the ratio of the sum total level of each fraction (Figure 3 ) to the total level of lead in the soil (Table 1), was $119 \pm 20 \%$. The composition of the control soil was as follows: $12.8 \%$ exchangeable fraction, $51.2 \%$ carbonate fraction, $20.7 \% \mathrm{Fe} / \mathrm{Mn}$ oxide fraction, 9.3\% organic fraction, and $6.0 \%$ residual fraction. The percentage of organic fraction 


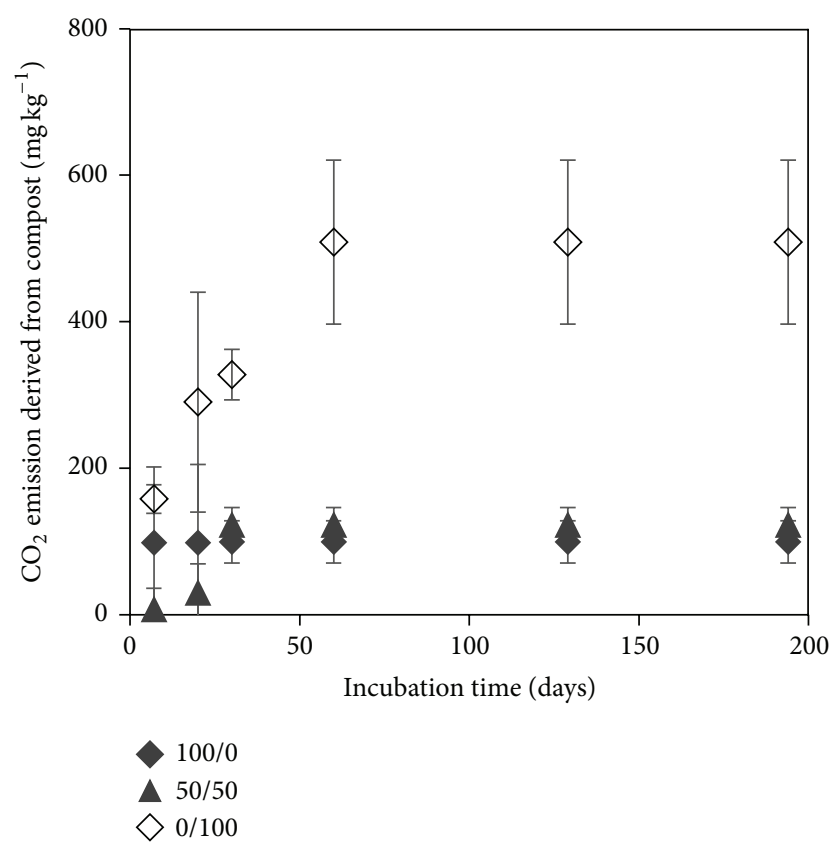

Figure 2: Cumulative $\mathrm{CO}_{2}$ emission derived from AMC with inorganic/organic $=100 / 0,50 / 50$, and $0 / 100$. Vertical bars indicate the standard error.

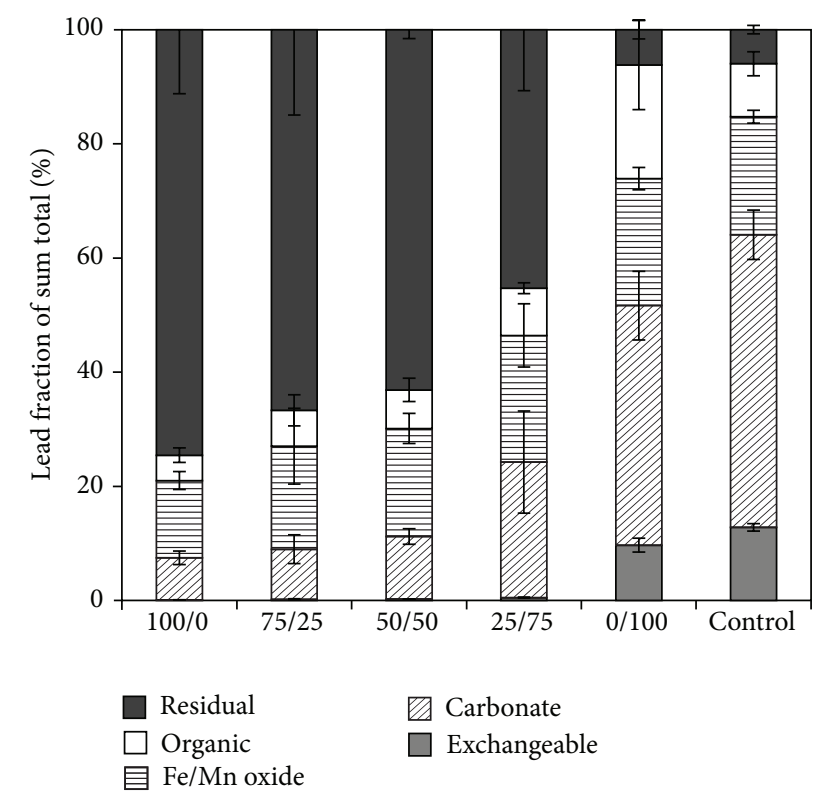

FIGURE 3: Sequential extraction of lead from soil amended with AMC of inorganic/organic $=100 / 0,75 / 25,50 / 50,25 / 75$, and 0/100 and without AMC (control) after 184 days of incubation. Vertical bars indicate the standard error.

by sequential extraction in the soil treated by AMC with an inorganic-to-organic ratio of 0/100 increased compared with that in the control soil, whereas that of carbonate decreased. The addition of AMC with a higher ratio of inorganic fraction resulted in a greater enhancement in the residual percentage. Furthermore, in soils with the AMCs containing an inorganic fraction of $25 \%$ or more, the percentage of organic fraction was at the same level as that in the control soil.

3.4. Microbial Enzyme Activities in Lead-Contaminated Soil. The dehydrogenase and urease activities in the soil treated by AMC with inorganic-to-organic ratios of $0 / 100$ and $25 / 75$, respectively, were significantly higher than that in the control soil; however, those in the soil treated by AMC with inorganic-to-organic ratios of 75/25 and 100/0 were significantly lower or on the same level (Figure 4).

\section{Discussion}

4.1. Role of Organic Component in Animal Manure Compost Lead Immobilization and Rehabilitation of Microbial Activity. The water-soluble lead level in the soil treated by AMC with an inorganic-to-organic ratio of $0 / 100 \mathrm{did}$ not become lower than that in the control soil during the incubation period (Figure 1(a)), whereas the lead phases in the soil by sequential extraction were altered to be more insoluble; the organic fraction was increased (Figure 3). Moreover, at the early stage of incubation, the water-soluble lead level remained at a higher level in the soil treated by AMC with an inorganicto-organic ratio of $25 / 75$. However, the water-soluble lead level decreased as the incubation time increased in soil with both composts. These observations would be explained by the higher level of water-soluble organic matter and its sorption and decomposition in the soil thereby increasing the incubation time. The water-soluble organic matter can easily form complexes with lead ions, and its complexes could enhance the lead mobility in the soil $[17,32,33]$. Therefore, at the early stage of incubation, the high level of water-soluble organic carbon would result in an enhancement of the lead mobility in the soil treated by AMC with inorganic-to-organic ratios of $0 / 100$ and $25 / 75$. The water-soluble organic matter was derived from the compost containing humic and fulvic acids with relatively low molecular weight $[34,35]$. These organic compounds are also readily decomposable and sorbed on the soil surface $[36,37]$. According to the result for $\mathrm{CO}_{2}$ emission (Figure 2), the amount of $\mathrm{CO}_{2}$ emission was lower than that of water-soluble organic carbon-decrease from day 0 to day 184 , suggesting that some of the water-soluble organic matter derived from the compost was decomposed and some of it was sorbed in the soil with the increase in the incubation period. Thus, the level of water-soluble lead would decrease with that water-soluble organic carbon in the soil treated by AMC with inorganic-to-organic ratios of $0 / 100$ and 25/75. It has been known that the compost amendment induced the very short-term leaching pulses of lead after the application [38], and lead was redistributed to the soil component by the decomposition of dissolved organic matter [39]. These results suggest that the organic component in the AMC does not considerably contribute to the immobilization of lead and suppression of lead mobility and bioavailability. This was comparable with the results of Schwab et al. [19] and Levonmäki et al. [40], who reported that water-soluble organic matter enhanced the lead mobility by the formation of complexation. However, all of the microbial enzyme activities 


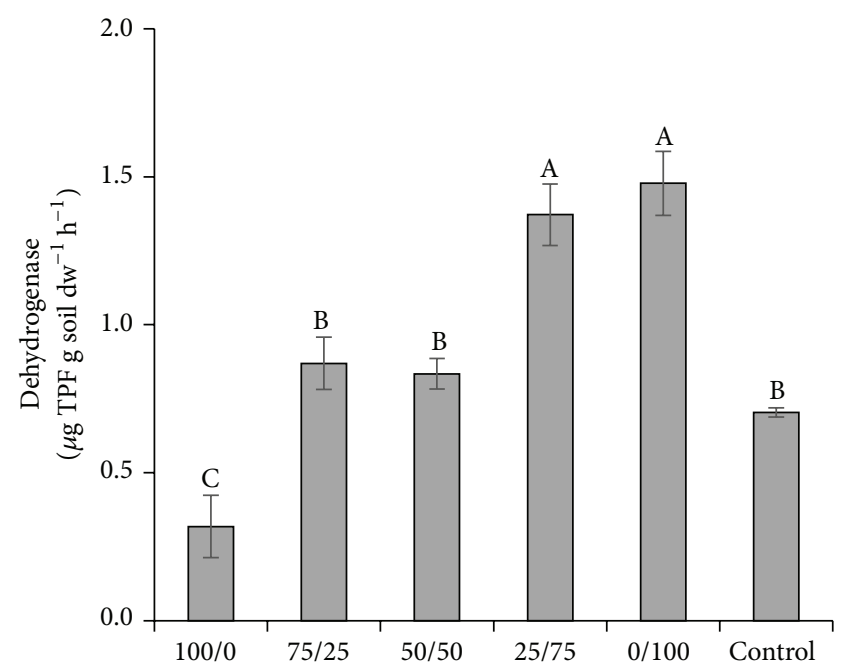

(a)

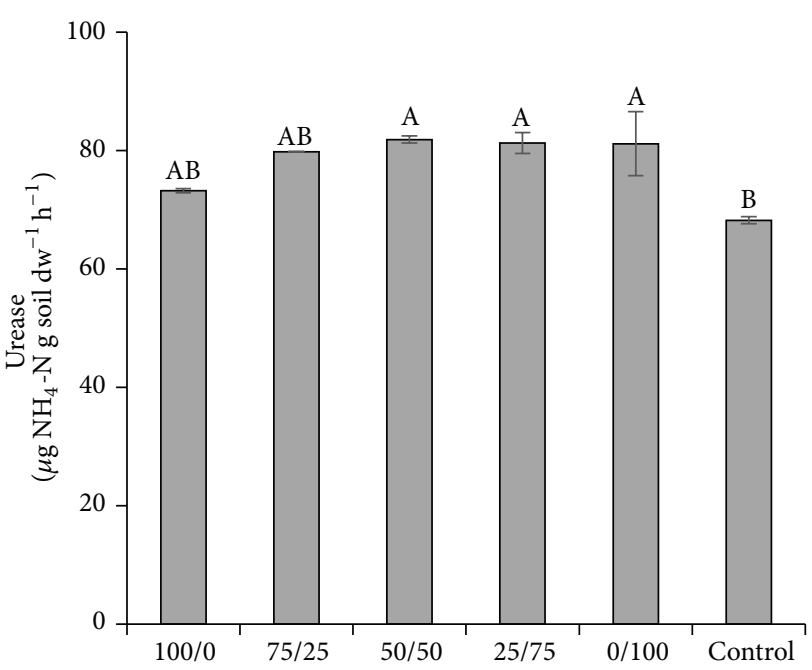

(b)

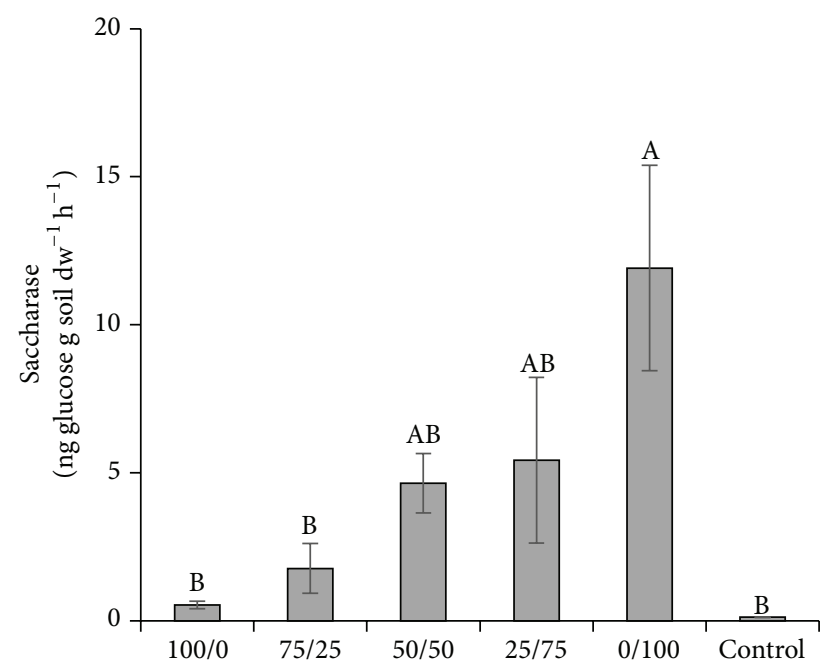

(c)

Figure 4: Enzyme activities of dehydrogenase (a), urease (b), and saccharase (c) in soil amended with AMC of inorganic/organic $=100 / 0$, 75/25, 50/50, 25/75, and 0/100 and without AMC (control) after 184 days of incubation. Vertical bars indicate the standard error. Different letters indicate significant difference at $P<0.05$.

measured herein increased in the soil treated by AMC with an inorganic-to-organic ratio of $0 / 100$, despite the fact that the level of water-soluble lead was higher. The dehydrogenase activity, which is an indicator of the overall microbial activity $[8,9,41-43]$, in the soil treated by AMC containing $50 \%$ or more inorganic fraction was the same level as that in the control soil, suggesting that the inorganic component in the AMC did not significantly contribute to the enhancement in the microbial activity, despite the fact that the lead mobility and bioavailability are greatly decreased by its addition. Farrell et al. [44] also showed that the microbial enzyme activities in the soil amended with the compost became higher than that in the inorganic material. The water-soluble organic matter derived from the compost is utilized as a nutrient source by microorganisms; thus, the addition of AMC with high organic matter content would induce the rehabilitation of microbial activity owing to the large amount of readily decomposable organic matter.

4.2. Role of the Inorganic Component in Animal Manure Compost on Lead Immobilization. The addition of AMC containing $50 \%$ or more inorganic fraction reduced the watersoluble lead by over $88 \%$ during the incubation period (Figure 1(a)). Moreover, the addition of AMC containing 25\% or more inorganic fraction could alter lead phases to be more insoluble. These results indicate that AMC containing $50 \%$ or more inorganic fraction could immobilize lead and reduce the lead bioavailability in the soil. The inorganic fraction used herein contained a considerable amount of phosphorus, which results in the precipitation of lead phosphate minerals such as pyromorphite [24]. Pyromorphite is thermodynamically stable with a solubility product of $\log K_{\mathrm{sp}}=$ 
-25.05 [45]. Therefore, the phosphorus in the AMC's inorganic component was responsible for the increase in the percentage of the residual fraction and decrease in the watersoluble lead level. This is supported by the results of Walker et al. [10], Liu et al. [11], and Clemente et al. [18], who suggested that the immobilization of lead and cadmium would be due to the precipitation of insoluble phosphate salts. The percentage of $\mathrm{Fe} / \mathrm{Mn}$ oxide and organic fractions by sequential extraction in the soil with AMC containing 25\% or more inorganic fraction was lesser than or approximately equal to that in the control soil, although the residual fraction increased with increase in the inorganic fraction ratio in AMC. Moreover, in the soil treated by AMC containing 50\% or less inorganic fraction, the level of water-soluble organic carbon was higher than that in the control soil. These results suggest that the phosphorus in the inorganic component of AMC could immobilize lead-precipitating lead phosphate minerals even if the AMC contained more organic than inorganic components. This may be because the magnitude of lead immobilization by the inorganic component of AMC suppressed the magnitude of the facilitation of lead mobility by the organic component in AMC.

The level of water-soluble lead in the soil treated by AMC with an inorganic-to-organic ratio of 25/75 was higher than that in the control soil during the first 30 days of incubation, whereas the lead phases were altered to be more insoluble. This was attributed to incomplete immobilization. Scheckel et al. [46] demonstrated that not all lead in soil could be immobilized by phosphorus material, according to extended $\mathrm{X}$-ray-absorption fine-structure analysis. The percentages of exchangeable and carbonate fractions by sequential extraction in the soil treated by AMC with an inorganic-to-organic ratio of $25 / 75$ were higher than that in the soil treated by AMC that was $50 \%$ or more inorganic fraction. The levels of water-soluble organic carbon in the soil treated by AMC with an inorganic-to-organic ratio 25/75 were also higher, particularly during the first 30 days of incubation. The higher amount of water-soluble organic matter formed complexes with lead dissolved from the exchangeable and carbonate fractions, resulting in an enhancement in the level of water-soluble lead in the early stage of incubation. With the increasing incubation time, water-soluble organic matter was decomposed and the level of water-soluble lead decreased below that in the control soil.

\subsection{Optimal Ratio of Inorganic and Organic Components} in Animal Manure Compost for Lead Immobilization and the Rehabilitation of Microbial Activity. Various inorganic percentages are used in the AMC, ranging from 7.3 to $82.8 \%$ [25]. The ranges of the inorganic fraction of AMC in this study fall within this range. On the basis of this study's findings, an inorganic component with a high phosphorus content of $50 \%$ or more is required to alter lead phases to be more insoluble and reduce the water-soluble lead level to less than that in the soil without compost, although the microbial activities are not enhanced. The importance of an inorganic component for the immobilization of heavy metals including lead in soil is pointed out by other researchers [21, 47, 48].
In contrast, $25 \%$ inorganic AMC can alter lead phases to be more insoluble and simultaneously enhance microbial activities, whereas the water-soluble lead level is higher than that in the soil without compost during the first 30 days after the application. This is consistent with the result of Katoh et al. [17], who indicated that the application of $25 \%$ inorganic swine manure compost could alter lead phases to be more insoluble and improve plant growth and microbial enzyme activities; however, the level of water-soluble lead was higher than that in the cattle manure compost during the early stage of incubation (90 days after application). These findings suggest that AMCs cannot immobilize both lead and restore microbial activity. Therefore, to immobilize lead and suppress the lead mobility and bioavailability using AMC, AMC that is $50 \%$ inorganic or more and contains a large phosphorus component should be applied to contaminated sites. However, in the case of low precipitation over a month, for example, during a dry season, $25 \%$ inorganic AMC should be used to both immobilize lead and restore microbial activity.

\section{Conclusion}

The amount of water-soluble lead in the soil treated by $100 \%$ organic AMC remained higher than that in the control soil throughout the 184-day incubation period, although it tended to decrease with increasing incubation time. The amount of water-soluble lead in the soil treated by AMC with an inorganic-to-organic ratio of 25/75 was higher than that in the soil without compost during the early stage of incubation, but it reached a lower level than that in the soil without compost after 90 days. The amounts of water-soluble lead in the soil treated by AMC containing $50 \%$ or more inorganic fraction were suppressed by over $88 \%$ from the value in the soil without compost and remained low throughout the incubation period. The reduction in the level of watersoluble lead in the soil treated by AMC with inorganic-toorganic ratios of $0 / 100$ and $25 / 75$ would be explained by the decomposition of water-soluble organic matter. The ratio of the residual fraction after sequential extraction was enhanced and the readily soluble lead fractions (exchangeable and carbonate fractions) were reduced in soils treated by AMC containing $25 \%$ or more inorganic fraction. In soil treated with fully organic AMC, the readily soluble lead fraction in sequential extraction did not change in comparison with that in the control soil, whereas the organic fraction in sequential extraction was enhanced. The compost containing $25 \%$ or less inorganic fraction could improve the microbial activity, but the compost containing $50 \%$ or more inorganic fraction could not. These results indicate that the compost containing 50\% or more inorganic fraction with a high phosphorus content is suitable for immobilizing lead and reducing lead mobility and bioavailability in the soil. However, to immobilize lead and improve the microbial activity at the same time, the AMC with $25 \%$ inorganic and $75 \%$ organic components should be used as a lead immobilization material, but note that higher lead mobility at the initial stage after the application should be considered. 


\section{Conflict of Interests}

The authors declare that there is no conflict of interests regarding the publication of this paper.

\section{Acknowledgments}

The ICP-AES and CHN elemental analyzer instruments used for the chemical analysis in this study were made available by the Division of Instrumental Analysis at Gifu University. The authors are grateful to Professor F. Li and Professor T. Yamada (Gifu University) for allowing the use of the TOC analyzer. This study was supported by the Japan Society for the Promotion of Science (JSPS) KAKENHI [Grant no. 23710089].

\section{References}

[1] D. J. Walker, R. Clemente, and M. P. Bernal, "Contrasting effects of manure and compost on soil $\mathrm{pH}$, heavy metal availability and growth of Chenopodium album L. in a soil contaminated by pyritic mine waste," Chemosphere, vol. 57 , no. 3, pp. 215-224, 2004.

[2] J. H. Park, N. Bolan, M. Megharaj, and R. Naidu, "Comparative value of phosphate sources on the immobilization of lead, and leaching of lead and phosphorus in lead contaminated soils," Science of the Total Environment, vol. 409, no. 4, pp. 853-860, 2011.

[3] X. Cao, A. Wahbi, L. Ma, B. Li, and Y. Yang, "Immobilization of $\mathrm{Zn}, \mathrm{Cu}$, and $\mathrm{Pb}$ in contaminated soils using phosphate rock and phosphoric acid," Journal of Hazardous Materials, vol. 164, no. 2-3, pp. 555-564, 2009.

[4] X. Cao, D. Dermatas, X. Xu, and G. Shen, "Immobilization of lead in shooting range soils by means of cement, quicklime, and phosphate amendments," Environmental Science and Pollution Research, vol. 15, no. 2, pp. 120-127, 2008.

[5] G. M. Hettiarachchi, G. M. Pierzynski, and M. D. Ransom, "In situ stabilization of soil lead using phosphorus and manganese oxide," Environmental Science and Technology, vol. 34, no. 21, pp. 4614-4619, 2000.

[6] A. Davis, L. E. Eary, and S. Helgen, "Assessing the efficacy of lime amendment to geochemically stabilize mine tailings," Environmental Science and Technology, vol. 33, no. 15, pp. 2626-2632, 1999.

[7] E. Lombi, F.-J. Zhao, G. Zhang et al., "In situ fixation of metals in soils using bauxite residue: chemical assessment," Environmental Pollution, vol. 118, no. 3, pp. 435-443, 2002.

[8] P. Alvarenga, A. P. Gonçalves, R. M. Fernandes et al., "Evaluation of composts and liming materials in the phytostabilization of a mine soil using perennial ryegrass," Science of the Total Environment, vol. 406, no. 1-2, pp. 43-56, 2008.

[9] P. Alvarenga, A. P. Gonçalves, R. M. Fernandes et al., "Organic residue as immobilizing agents in aided phytostabilization: (I) Effects on soil chemical characteristics," Chemosphere, vol. 74, no. 10, pp. 1292-1300, 2009.

[10] D. J. Walker, R. Clemente, A. Roig, and M. P. Bernal, “The effects of soil amendments on heavy metal bioavailability in two contaminated Mediterranean soils," Environmental Pollution, vol. 122, no. 2, pp. 303-312, 2003.

[11] L. Liu, H. Chen, P. Cai, W. Liang, and Q. Huang, "Immobilization and phytotoxicity of $\mathrm{Cd}$ in contaminated soil amended with chicken manure compost," Journal of Hazardous Materials, vol. 163, no. 2-3, pp. 563-567, 2009.

[12] A. Sato, H. Takeda, W. Oyanagi, E. Nishihara, and M. Murakami, "Reduction of cadmium uptake in spinach (Spinacia oleracea L.) by soil amendment with animal waste compost," Journal of Hazardous Materials, vol. 181, no. 1-3, pp. 298-304, 2010.

[13] H.-S. Chen, Q.-Y. Huang, L.-N. Liu, P. Cai, W. Liang, and M. Li, "Poultry manure compost alleviates the phytotoxicity of soil cadmium: influence on growth of pakchoi (Brassica chinensis L.)," Pedosphere, vol. 20, no. 1, pp. 63-70, 2010.

[14] R. Clemente, C. Almela, and M. P. Bernal, "A remediation strategy based on active phytoremediation followed by natural attenuation in a soil contaminated by pyrite waste," Environmental Pollution, vol. 143, no. 3, pp. 397-406, 2006.

[15] E. Doelsch, A. Masion, G. Moussard, C. Chevassus-Rosset, and O. Wojciechowicz, "Impact of pig slurry and green waste compost application on heavy metal exchangeable fractions in tropical soils," Geoderma, vol. 155, no. 3-4, pp. 390-400, 2010.

[16] R. P. Narwal and B. R. Singh, "Effect of organic materials on partitioning, extractability and plant uptake of metals in an alum shale soil," Water, Air, and Soil Pollution, vol. 103, no. 1-4, pp. 405-421, 1998.

[17] M. Katoh, W. Kitahara, R. Yagi, and T. Sato, "Suitable chemical properties of animal manure compost to facilitate $\mathrm{Pb}$ immobilization in soil," Soil and Sediment Contamination, vol. 23, no. 5, pp. 523-539, 2014.

[18] R. Clemente, Á. Escolar, and M. P. Bernal, "Heavy metals fractionation and organic matter mineralisation in contaminated calcareous soil amended with organic materials," Bioresource Technology, vol. 97, no. 15, pp. 1894-1901, 2006.

[19] P. Schwab, D. Zhu, and M. K. Banks, "Heavy metal leaching from mine tailings as affected by organic amendments," Bioresource Technology, vol. 98, no. 15, pp. 2935-2941, 2007.

[20] R. Clemente and M. P. Bernal, "Fractionation of heavy metals and distribution of organic carbon in two contaminated soils amended with humic acids," Chemosphere, vol. 64, no. 8, pp. 1264-1273, 2006.

[21] A. Baghaie, A. H. Khoshgoftarmanesh, M. Afyuni, and R. Schulin, "The role of organic and inorganic fractions of cow manure and biosolids on lead sorption," Soil Science and Plant Nutrition, vol. 57, no. 1, pp. 11-18, 2011.

[22] S. Deiana, C. Gressa, B. Manunza, R. Rausa, and R. Seever, "Analytical and spectroscopic characterization of humic acids extracted from sewage sludge, manure, and worm compost," Soil Science, vol. 150, no. 1, pp. 419-424, 1990.

[23] M. A. A. Zaini, R. Okayama, and M. Machida, "Adsorption of aqueous metal ions on cattle-manure-compost based activated carbons," Journal of Hazardous Materials, vol. 170, no. 2-3, pp. 1119-1124, 2009.

[24] M. Katoh, W. Kitahara, and T. Sato, "Sorption of lead in animal manure compost: contributions of inorganic and organic fractions," Water, Air, and Soil Pollution, vol. 225, no. 1, article 1828, 2014.

[25] T. Yamaguchi, Y. Harada, and M. Tsuiki, "Basic data of animal waste composts," Miscellaneous Publication of the National Agriculture Research Center, vol. 41, pp. 1-178, 2000 (Japanese).

[26] G. W. Gee and J. M. Bauder, "Partical-size analysis," in Methods of Soil Analysis, Part 1, A. L. Page, R. H. Miller, and D. R. Keeney, Eds., pp. 383-411, American Society of Agronomy, Madison, Wis, USA, 1986.

[27] L. M. Shuman, "Fractionation method for soil microelements," Soil Science, vol. 140, no. 1, pp. 11-22, 1985. 
[28] A. Tessier, P. G. C. Campbell, and M. Blsson, "Sequential extraction procedure for the speciation of particulate trace metals," Analytical Chemistry, vol. 51, no. 7, pp. 844-851, 1979.

[29] M. A. Tabatabai, "Soil enzymes," in Methods of Soil Analysis, Part 2, S. H. Mickelson and J. M. Bigham, Eds., pp. 77-83, American Society of Agronomy, Madison, Wis, USA, 1994.

[30] E. Kandeler and H. Gerber, "Short-term assay of soil urease activity using colorimetric determination of ammonium," Biology and Fertility of Soils, vol. 6, no. 1, pp. 68-72, 1988.

[31] W. T. Frankenberger and J. B. Johanson, "Method of measuring invertase activity in soils," Plant and Soil, vol. 74, no. 3, pp. 313323, 1983.

[32] S. Sauvé, M. McBride, and W. Hendershot, "Soil solution speciation of lead (II): effects of organic matter and pH,' Soil Science Society of America Journal, vol. 62, no. 3, pp. 618-621, 1998.

[33] H. Wang, X. Shan, T. Liu et al., "Organic acids enhance the uptake of lead by wheat roots," Planta, vol. 225, no. 6, pp. 14831494, 2007.

[34] M. Aoyama, "Fractionation of water-soluble organic substances formed during plant residue decomposition and high performance size exclusion chromatography of the fractions," Soil Science and Plant Nutrition, vol. 42, no. 1, pp. 31-40, 1996.

[35] M. Aoyama, "Properties of fine and water-soluble fractions of several composts II. Organic forms of nitrogen, neutral sugars, and muramic acid in fractions," Soil Science and Plant Nutrition, vol. 37, no. 4, pp. 629-637, 1991.

[36] T. Paré, H. Dinel, M. Schnitzer, and S. Dumontet, "Transformations of carbon and nitrogen during composting of animal manure and shredded paper," Biology and Fertility of Soils, vol. 26, no. 3, pp. 173-178, 1998 .

[37] D. L. Jones and D. S. Brassington, "Sorption of organic acids in acid soils and its implications in the rhizosphere soil," European Journal of Soil Science, vol. 49, pp. 447-455, 1998.

[38] M. Farrell, W. T. Perkins, P. J. Hobbs, G. W. Griffith, and D. L. Jones, "Migration of heavy metals in soil as influenced by compost amendments," Environmental Pollution, vol. 158, no. 1, pp. 55-64, 2010.

[39] A. W. Schroth, B. C. Bostick, J. M. Kaste, and A. J. Friedland, "Lead sequestration and species redistribution during soil organic matter decomposition," Environmental Science \& Technology, vol. 42, no. 10, pp. 3627-3633, 2008.

[40] M. Levonmäki, H. Hartikainen, and T. Kairesalo, "Effect of organic amendment and plant roots on the solubility and mobilization of lead in soils at a shooting range," Journal of Environmental Quality, vol. 35, no. 4, pp. 1026-1031, 2006.

[41] A. Pérez-de-Mora, P. Burgos, E. Madejón, F. Cabrera, P. Jaeckel, and M. Schloter, "Microbial community structure and function in a soil contaminated by heavy metals: effects of plant growth and different amendments," Soil Biology and Biochemistry, vol. 38, no. 2, pp. 327-341, 2006.

[42] S. Doni, C. MacCi, E. Peruzzi, M. Arenella, B. Ceccanti, and G. Masciandaro, "In situ phytoremediation of a soil historically contaminated by metals, hydrocarbons and polychlorobiphenyls," Journal of Environmental Monitoring, vol. 14, no. 5, pp. 1383-1390, 2012.

[43] J. Wyszkowska, J. Kucharski, and W. Lajszner, "The effects of copper on soil biochemical properties and its interaction with other heavy metals," Polish Journal of Environmental Studies, vol. 15, no. 6, pp. 927-934, 2006.
[44] M. Farrell, G. W. Griffith, P. J. Hobbs, W. T. Perkins, and D. L. Jones, "Microbial diversity and activity are increased by compost amendment of metal-contaminated soil," FEMS Microbiology Ecology, vol. 71, no. 1, pp. 94-105, 2010.

[45] P. Miretzky and A. Fernandez-Cirelli, "Phosphates for $\mathrm{Pb}$ immobilization in soils: a review," Environmental Chemistry Letters, vol. 6, no. 3, pp. 121-133, 2008.

[46] K. G. Scheckel, J. A. Ryan, D. Allen, and N. V. Lescano, "Determining speciation of $\mathrm{Pb}$ in phosphate-amended soils: method limitations," Science of the Total Environment, vol. 350, no. 1-3, pp. 261-272, 2005.

[47] P. Castaldi, L. Santona, and P. Melis, "Heavy metal immobilization by chemical amendments in a polluted soil and influence on white lupin growth," Chemosphere, vol. 60, no. 3, pp. 365-371, 2005.

[48] A. Ruttens, M. Mench, J. V. Colpaert, J. Boisson, R. Carleer, and J. Vangronsveld, "Phytostabilization of a metal contaminated sandy soil. I: influence of compost and/or inorganic metal immobilizing soil amendments on phytotoxicity and plant availability of metals," Environmental Pollution, vol. 144, no. 2, pp. 524-532, 2006. 

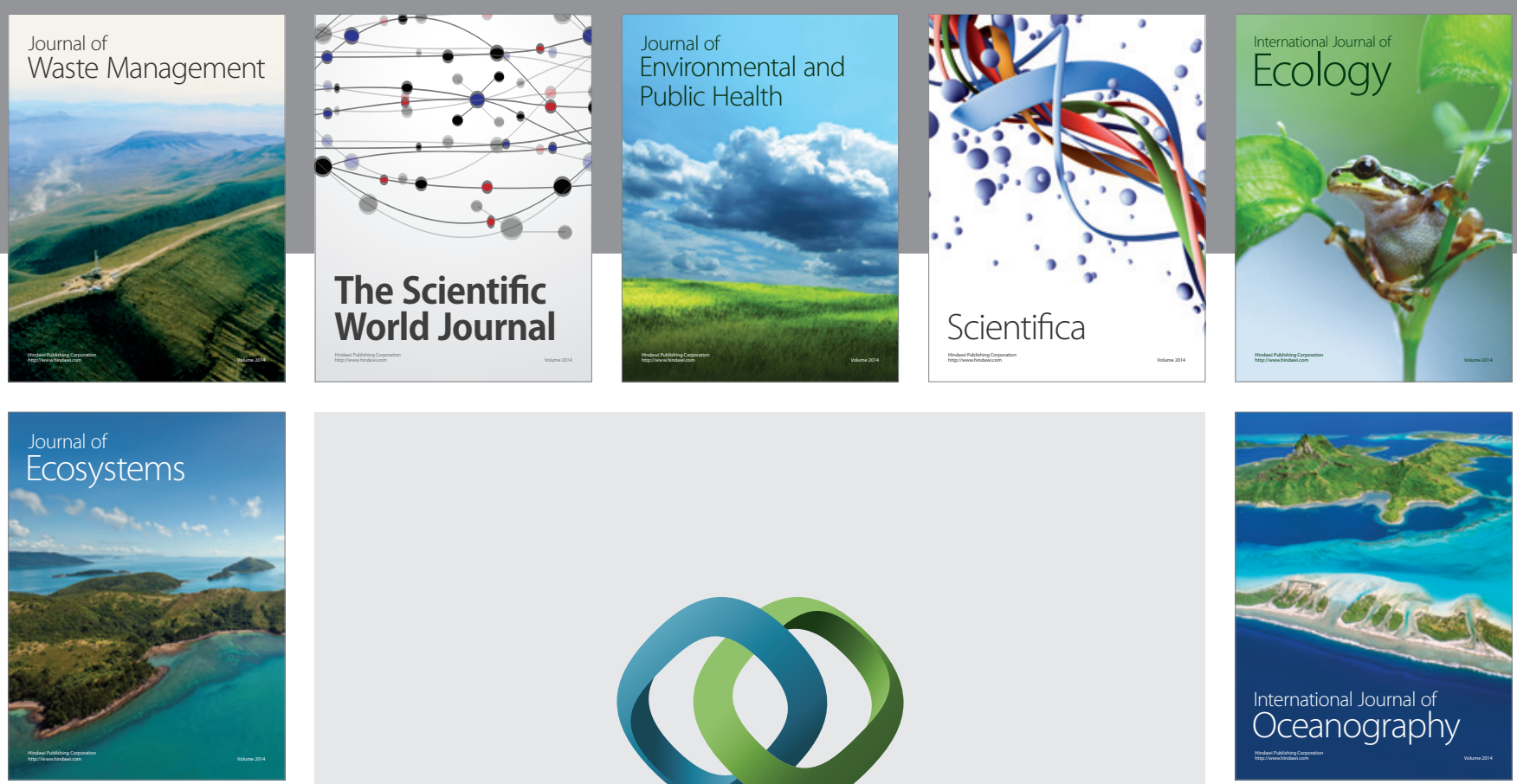

The Scientific World Journal
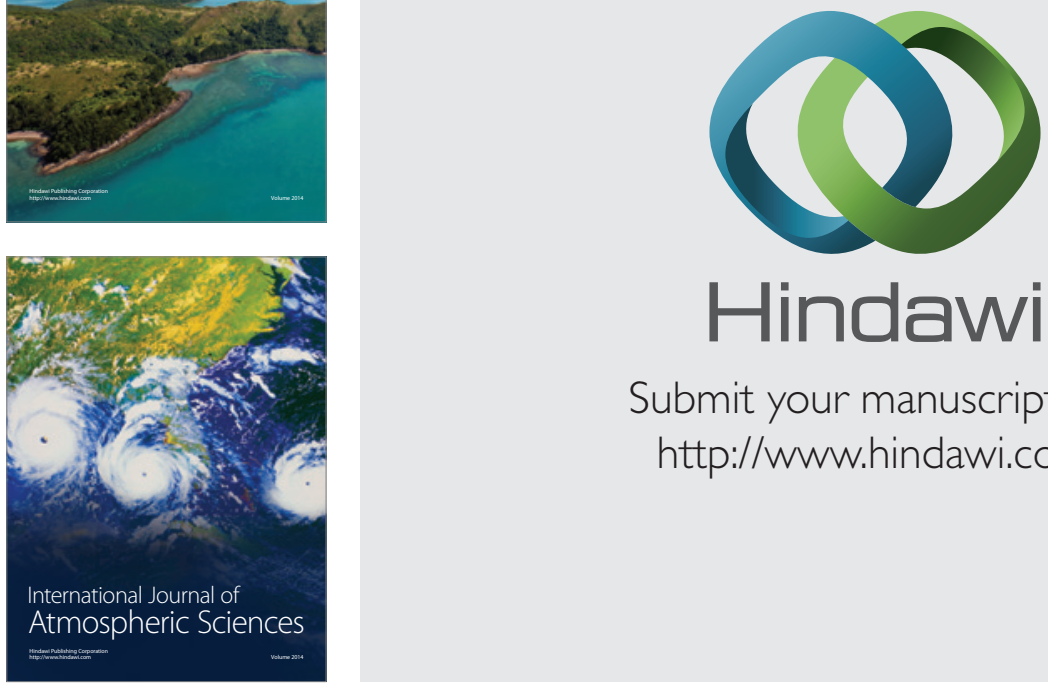

\section{Hindawi}

Submit your manuscripts at

http://www.hindawi.com
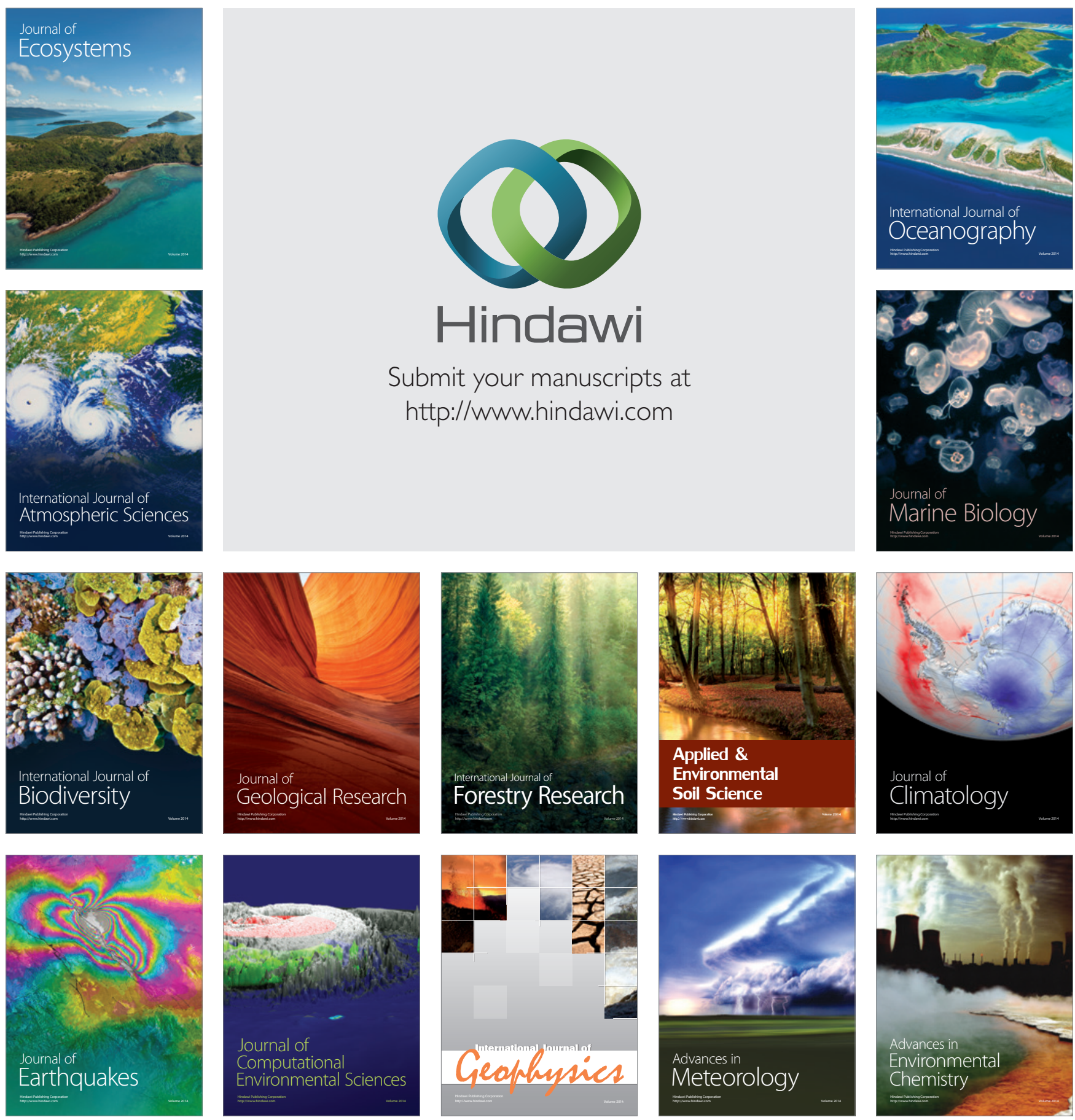